\title{
Descriptions and non-doxastic attitude ascriptions
}

\author{
Wojciech Rostworowski ${ }^{1,2}$
}

(C) The Author(s) 2017. This article is an open access publication

\begin{abstract}
This paper addresses a certain objection to the quantificational theory of definite descriptions. According to this objection, the quantificational account cannot provide correct interpretations of definite descriptions embedded in the nondoxastic attitude ascriptions and therefore ought to be rejected. In brief, the objection says that the quantificational theory is committed to the view that a sentence of the form "The $\mathrm{F}$ is $\mathrm{G}$ " is equivalent to the claim that there is a unique $\mathrm{F}$ and it is $G$, while the ascription such as, e.g., "S wants the $F$ to be $G$ " is not equivalent to the statement that $S$ wants there to be a (unique) $F$ and for it to be G. I argue that this objection is invalid as it rests on a false assumption concerning the substitutivity of the relative clauses in the non-doxastic attitude ascriptions.
\end{abstract}

Keywords Definite descriptions · Propositional attitudes · Quantificational account $\cdot$ Substitutivity

\section{Introduction}

According to the quantificational theory of indefinite and definite descriptions, these phrases are not genuinely referring expressions, but are incomplete symbols which introduce a complex quantificational structure into a sentence in which they occur. In particular, the semantic analyses of subject-predicate sentences can be represented as follows:

Wojciech Rostworowski

wrostwor@wp.pl

1 Institute of Philosophy, Faculty of Philosophy and Sociology, University of Warsaw, Krakowskie Przedmiescie 3, Warsaw 00-927, Poland

2 Adama Pluga 1/88, Warsaw 02-047, Poland 
(1) $\mathrm{A}$ /an $F$ is $G=[$ An $x: F(x)] G(x)$

The $F$ is $G=[$ The $x: F(x)] G(x)^{1}$

Accordingly, a sentence of the form "A/an $F$ is $G$ " expresses the proposition equivalent to the claim that there exists an object which has the property expressed in the nominal " $F$ " and the property expressed in the predicate " $G$ "; a sentence with a definite description is equivalent to the claim that there is exactly one $F$ and it is $G$.

In spite of the fact that the quantificational theory is said to have many remarkable advantages, ${ }^{2}$ it has raised several objections. Among other things, some theorists have argued that the theory predicts incorrect truth conditions of the socalled "non-doxastic" attitude ascriptions - that is, the ascriptions of attitudes such as desires, hopes and fears etc.--where descriptions are embedded. ${ }^{3}$ Here is the objection. Imagine that Hans lives in an old house with a big attic and believes that the attic is haunted. Suppose that Hans is not happy about this situation since he is afraid of ghosts. One night, our hero has to finish his thesis and so wishes the ghost would be quiet. It seems perfectly natural for us to report his wish using the following sentence:

(2) Hans wants the ghost in his attic to be quiet tonight.

Since we do not want to commit ourselves to the belief that there is a ghost is Hans's attic (that is, we want to make a "de dicto" report), a proponent of the quantificational theory should ascribe the narrow-scope interpretation to our ascription, i.e., "Hans wants that [The $x$ : Ghost $(x)]$ Quiet $(x)$ " which seems to be plainly equivalent to:

(3) Hans wants there to be a unique ghost in his attic and for it to be quiet.

However, this reading is incorrect in the light of the earlier background assumption. The problem is that (3) clearly implies that Hans wishes that there would exist a unique ghost in his attic. But this is inconsistent with the contextual information. Namely, Hans is afraid of ghosts and does not want to have any ghosts in his attic. It seems then that (3) is simply false in the presented context, while (2) is intuitively true.

The above conclusion can be generalized. Namely, the quantificational theory of descriptions delivers incorrect interpretations of ascriptions such as " $S$ wants the $F$ to be $G$,", " $S$ fears that the $F$ is $G$ " etc. when (i) the speaker is making a "de dicto" ascription, (ii) $S$ does not bear a given attitude towards the existence of the $F^{4}$

\footnotetext{
${ }^{1}$ Here I use Neale's restricted-quantifier notation (for details see Neale 1990, sec. 2.5 and 2.6).

2 See Russell (1905) or Neale (1990, 2005).

3 For example, see Elbourne (2005: 109-112, 2010) and Schoubye (2013). A defense of the quantificational theory is presented by Pupa (2013).

4 I illustrate the objection based on the famous example with definite descriptions. As Ramachandran (2009) and Schoubye (2013: 506-508) observe, the problem also concerns indefinite descriptions. However, Elbourne (2013: 159-167) argues that indefinite descriptions are not problematic for Russell's theory in the way in which definites are.
} 
Based on the above observations, the opponents of the quantificational approach conclude that this approach is basically wrong, namely, it ascribes incorrect truth conditions to "The $F$ is $G$ " (see: Elbourne 2010: 2-3, Schoubye 2013: 498-499). In other words, they argue that the following statements do not actually have the same truth conditions:

(4) a. The $F$ is $G$.

b. There is a unique $F$ and it is $G$.

In short: if sentences of the subject-predicate form indicated in (4.a) and the corresponding "existential-there" sentences of the form indicated in (4.b) shared the truth conditions, then (2) should preserve its truth conditions once we replace the embedded subject-predicate clause with the corresponding existential sentence. However, as the earlier example shows, this is not generally the case; hence the subject-predicate sentences and the "existential-there" sentences have different truth conditions.

The aim of this paper is the following. I am going to show that the above objection is not a valid argument against the quantificational theory. In the first part of Sect. 1, I will argue that a proponent of this theory is actually committed to the view that subject-predicate sentences and the corresponding existential sentences have the same truth conditions but not to the view that they have the same logical forms. Subsequently, I will present some evidence for the claim that non-doxatic attitude operators, such us " $S$ wants that..." are hyper-intensional to the extent that they do not generally allow for substitutions of equivalent statements with different logical forms in their scope. Section 2 will discuss the problem what features of non-doxastic attitudes ascriptions prevent such substitutions. Finally, in Sect. 3, I will address the question of how this problem is related to a similar objection raised against the quantificational theory, which concerns conditionals.

\section{Principle of substitutivity}

Let me start my considerations by recalling one particular defense of the quantificational theory of descriptions against the presented objection, which has been suggested by some theorists. This will be a good starting point for the further analysis of non-doxastic attitude ascriptions.

\subsection{Assumptions that underlie the objection}

Kaplan (2005: 985) and Neale (2005: 846) argue that the objection involving nondoxastic attitudes is not convincing as it relies on a certain false principle concerning the ascriptions of such attitudes. As we remember, the claim that (3) does not capture the meaning of (2) is based on the observation that (3) implies that Hans actually wants there to be a ghost in his attic, while (2) does not make such a commitment. Strictly speaking, the argument seems to presume that (3) (repeated here as 3.a) is different from (2) with respect to the fact that it entails (3.b): 
(3) a. Hans wants there to be a unique ghost in his attic and for it to be quiet. $\vDash$

b. Hans wants there to be a ghost in his attic.

Observe that the relative clause in (3.b) is-from the viewpoint of the quantificational analysis - a logical consequence of the relative clause in (3.a). Hence, we may conclude that the problematic conclusion relies on a principle saying that nondoxastic operators are closed under logical entailments. This principle (henceforth, "the Closure Principle") can be formulated as follows:

(5) If $\mathrm{S}$ bears a (non-doxastic) attitude $A$ towards $p$ and $p$ entails $q$, then $S$ bears $A$ towards $q$.

However, as Kaplan and Neale demonstrate, the Closure Principle is not generally valid. Here are two counterexamples:

(6) a. Diogenes wonders whether there are honest men. I $\neq$

b. Diogenes wonders whether there are men (Kaplan 2005: 985).

(7) a. Brown wants Smith's murderer to be convicted. I $\neq$

b. Brown wants Smith to be murdered (Stalnaker 1984: 89).

Thus the objection concerning the attitude ascriptions is not valid since it is basedaccording to Kaplan and Neale-on the Closure Principle which is false in the light of the above counterexamples.

Nonetheless, the opponents of the quantificational approach have neatly responded to Kaplan's and Neale's defenses by claiming that the objection involving attitude ascriptions does not actually require the Closure Principle. As Elbourne (2010: 7) argues, the problem with the quantificational reading can be formulated as follows: according to this reading, a sentence of the form "The $F$ is $G$ " has the meaning of "There is a unique $F$ and it is $G$ "; so ascriptions (2) and (3) should have the same truth conditions, but apparently they do not. The fact that they have different truth conditions becomes clear when we consider both sentences in a wider linguistic context, e.g.

(8) Hans wonders whether there is a ghost in his attic.

a. He wants there to be a unique ghost and for it to be quiet.

b. \# He wants the ghost in the attic to be quiet.

The continuation of (8) with (a) sounds correct while the continuation with (b) is clearly infelicitous as it ascribes somehow inconsistent attitudes to Hans. This observation suffices to conclude that (2) is actually not equivalent to (3) and thus the quantificational theory is wrong. Observe now that no piece of this reasoning mentions the Closure Principle. In other words, the problem with the non-doxastic attitude ascriptions is not actually related to the Closure Principle and, for that reason, Kaplan's/Neale's defense of the quantificational theory is ineffective.

As I have said, recalling Kaplan's/Neale's critique is a good point to start my discussion. This is because-although their particular argument fails-it indicates, in my opinion, the right track for the course of a critical examination of the problem. Namely, the objection involving non-doxastic attitudes makes a certain assumption 
that is not generally true as far as non-doxastic attitudes are concerned. To begin with, let us observe that the objection appeals to the fact that the quantificational theory treats subject-predicate and the corresponding there-existential sentences [(4.a) and (4.b)] as equivalent. Indeed, it seems to be the core of Russellian view presented in "On Denoting" (1905) that a simple subject-predicate clause is to be analyzed as a complex existential claim and the latter presents the true logical form of the former. However, looking at the quantificational approach through the prism of the original Russellian formulation of the theory is somehow misleading. It was a big insight of Neale's analysis of the quantificational approach in "Descriptions" (1990) that one can accept Russellian truth conditions not being committed to Russellian analysis of the logical form. Actually, Neale claims that an adequate semantic theory for natural language should abandon Russell's way of paraphrasing the logical form of subject predicate sentences in terms of unary quantifiers (and logical connectives) for several reasons (see: 1990: 39-40). Taking Neale's point of view, we can say that subject-predicate sentences and existential-there sentences have actually two different logical forms despite having the same truth conditions. Let us say that two sentences are "analytically equivalent" in the sense that they have the same truth conditions but different logical forms. I suppose then the proponent of the quantificational approach can say that subject-predicates and the corresponding existentials are analytically equivalent.

Let us now come back to the objection concerning the non-doxastic attitudes. The objection says that when we replace a subject-predicate clause with the appropriate existential clause in a non-doxastic attitude ascription, the ascription will change its truth conditions. In light of the above claim-that it is enough for the quantificational theory to accept merely analytical equivalence of the two types of clauses-one can realize that the objection actually requires an additional assumption in order to target the quantificational approach. Namely, the objection needs a principle saying that two analytically equivalent sentences are salva veritate interchangeable in the scope of a non-doxastic attitude ascription. In other words,

(9) If $S$ bears a non-doxastic attitude $A$ towards $p$ and $p$ is analytically equivalent to $q$, then $S$ bears $A$ towards $q$.

I will now argue that the above principle (henceforth, "the Substitutivity Principle"), though seems to be very plausible, encounters serious counterexamples. What is more, I will try to demonstrate in the next section that the cases where the principle fails to exhibit, in fact, a general pattern into which the pair "subjectpredicates/existential sentences" actually fall. ${ }^{5}$

\subsection{Problems with Substitutivity Principle}

I will start by considering the following pairs of statements:

\footnotetext{
5 Schoubye (2013: 3) notes that the problem with non-doxastic attitude ascriptions concerns Neale's analysis, as well as Russell's, since both accounts predict exactly the same truth conditions. As we will see, it is the aspect of the logical form which matters and not the aspect of the truth conditions of subjectpredicate and existential sentences.
} 
(10) a. Jones lost the game honorably.

b. Jones lost the game and he did it honorably.

(11) a. Sarah is only 5 min late.

b. Sarah is late and her delay is only $5 \mathrm{~min}$.

The (a)-sentences seem to say the same thing as the corresponding (b)-sentences in each pair, though in different words. Namely, these pairs clearly comprise analytically equivalent sentences. Let us now see what happens when we embed these sentences in the scope of a non-doxastic attitude verb:

(12) a. Jones wants to lose the game honorably.

b. Jones wants to lose the game and to do it honorably.

(13) a. I hope that Sarah will be only 5 min late.

b. I hope that Sarah will be late and her delay will be only $5 \mathrm{~min}$.

As we may observe, the resulting complex (a)-sentences do not have the same truth conditions as the corresponding (b)-sentences. For example, (12.a) would be true in a situation in which Jones is aware that he has no chance of winning (let us say that he is playing chess with a chess-master and although he is trying his best, he slowly loses his pieces to the opponent); nevertheless, when offered some tips, Jones refuses assistance saying: "I don't need any help. I want to lose honorably!". On the other hand, (12.b) clearly implies that it is a part of Jones's desire to lose ("he wants to lose and to do it honorably") so this ascription would be false in the described circumstances. A similar point can be made about (13). In light of such examples, we see that the Substitutivity Principle actually fails. That is, there are cases where $S$ bears a (non-doxastic) attitude $A$ towards $p$ which is analytically equivalent to $q$, but $S$ does not bear $A$ towards $q$.

The presented examples and the conclusion about the principle failure undoubtedly require an extensive commentary. I will turn to this issue in the next section. Before that, let me formulate a conclusion which follows directly from the fact that the Substitutivity Principle does not hold without any restriction. In brief, this conclusion says that the observation that ascriptions (2) and (3) (repeated below) have different truth conditions does not suffice to establish that their embedded clauses have different truth conditions themselves:

(2) Hans wants the ghost in the attic to be quiet tonight,

(3) Hans wants there to be a unique ghost in his attic and for it to be quiet.

As we have observed, two analytically equivalent statements may generate different readings when being embedded in such ascriptions. Hence, in spite of the fact that according to the quantificational theory, the relative clauses in (2) and (3) are analytically equivalent, we cannot reject this theory by saying that both clauses generate non-equivalent readings in the scope of a non-doxastic attitude verb. In short, the objection involving non-doxastic attitudes is not logically valid.

Provided that the Principle of Substitutivity fails, the discussed objection requires some additional assumptions in order to show that the quantificational theory is wrong. But perhaps it may work under some reasonable additional assumptions. 
Moreover, the conclusion that the principle has some counterexamples does not justify the fact that it presumably holds when we introduce appropriate restrictions and it may apply to (2) and (3) even under these restrictions. After all, it looks like a very plausible principle so the question arises why it actually fails. In the remainder of this paper, I will attempt to address this issue to a certain degree.

\section{Non-doxastic attitude ascriptions and analytically equivalent statements}

I will begin with some clarifications of my view. Firstly, by claiming that the Principle of Substitutivity does not hold, I do not mean its blanket failure. On the contrary, I believe that it only fails when some specific conditions are met. Secondly, I do not maintain that non-doxastic attitude operators prevent substitution of the embedded clauses that have the same semantic contents. Yet again, I believe the opposite-namely, that the semantic contents of the embedded clauses must manifest a difference (although this difference does not amount to the difference in truth conditions) in the cases where they produce substitutivity failure. Furthermore, I am aware that the recognized phenomenon illustrated by (12) and (13) is not completely unfamiliar as it has been discussed in the investigation of presupposition projection (e.g., see Heim 1992: 194-195). However, I believe that the particular explanation offered in the discussion concerning presuppositions is not satisfactory for the reasons presented in a moment.

\subsection{Are presuppositions the key?}

I will start with the following hypothesis. Looking at the earlier examples, one may say that the difference in the truth conditions of the ascriptions such as (12.a) and (12.b) lies, in fact, in a difference in presuppositions of the embedded clauses. Indeed, it is easy to illustrate the problem with using a textbook example of a pair of sentences with different presuppositions, e.g.,

(14) a. Brad stopped smoking.

b. Brad smoked and he stopped smoking.

Observe now that, for instance, wondering whether (14.a) is the case is not the same as wondering whether (14.b) is the case. Generally speaking, non-doxastic attitude ascriptions with (14.a) and (14.b) as the relative clauses have different truth conditions. It seems that much the same explanation would hold for the earlier examples. It is standardly assumed that (11.a) presupposes that Sarah is late while (11.b) does not trigger such a presupposition. Likewise, we may try to explain the difference between (10.a) and (10.b). As some theorists have argued, adverbs of manner are presupposition-triggers in the sense that a sentence of the form " $S$ Ves $A D$ ly" presupposes that $S$ Ves (see: Abbott 2000). In sum, the hypothesis is that the truth-conditional asymmetry between (12.a) and (12.b), or between (13.a) and (13.b), is a result of presuppositional differences of their embedded clauses. 
The above hypothesis can actually provide a precise explanation why the Substitutivity Principle fails in the considered cases. Namely, we are able to explain the truth-conditional asymmetry between these ascriptions by an appeal to some well-established facts about "presupposition projection". In brief, if $p$ presupposes $q$, then a sentence of the form " $S$ wants that $p$ " (or with a similar non-doxastic attitude verb) presupposes that $S$ believes that $q$ (see: Karttunen 1974; Heim 1992). For example, the statement that Joan wants Brad to stop smoking presupposes that Joan actually believes that Brad smokes. This observation is enough to justify the difference between (2) and (3) as embedded in the context of (8) (repeated below):

(8) Hans wonders whether there is a ghost in his attic.

a. He wants there to be a unique ghost and for it to be quiet.

b. \# He wants the ghost in the attic to be quiet.

Namely, the second statement (8.b) is infelicitous because it triggers a presupposition that Hans believes that there is a ghost, which contradicts the first part of the utterance, i.e., that Hans wonders whether there is a ghost. Altogether, the difference between (2) and (3) — and ascriptions (12)-(13) as well-is explained by a theory of presupposition projection.

Once we grant that the presuppositional analysis is the key to the truthconditional asymmetry between pairs such as (2) and (3), it will be bad news for the quantificational theory of descriptions. This is because, in a standard version, this theory does not claim that descriptions have existential presuppositions. In particular, for a diehard Russellianist, subject-predicate and existential-there sentences do not differ in presuppositions. Hence, if (i) the apparent substitutivity failure is strictly related to the difference in presuppositions of the embedded clauses, (ii) from the viewpoint of Russellianism, the presuppositions of the embedded clauses in (2) and (3) are identical, then how can Russellianism explain the truth conditional asymmetry between these ascriptions?

Nonetheless, I believe that the presented objection to Russellianism is not effective since the above considerations have been on a wrong track from the very beginning. Namely, I do not think that the problem with the Principle of Substitutivity can be explained away in terms of presuppositional differences of the embedded clauses in attitude ascriptions. Let me start with an observation provided by Schoubye (2013: 514-15). ${ }^{6}$ The author considers a theory which combines the quantificational analysis with the presuppositional one- the view which claims both that subject-predicate sentences have Russellian truth conditions and that a use of "the $F$ " imposes the requirement that it is common ground that there is a unique $F$. Given such a view, we are ready to explain the contrast in (8). However, the problem has not been solved at all. The point is that if there were only a presuppositional difference between (2) and (3) (i.e., they both have the same content but the former presupposes that Hans believes in the existence of a unique ghost, while the latter does not), they both should have the same truth value under

\footnotetext{
${ }^{6}$ As we will see in a moment, this argument borrowed from Schoubye requires some elaboration. I am indebted to an anonymous referee for recognizing that the argument in the previous version fails.
} 
the supposition that this presupposition is satisfied-or so Schoubye claims. Yet, even in such a case, the truth-conditional difference emerges. Let us compare (15.a) and (15.b) below:

(15) Hans believes that there is a unique ghost and

a. he wants there to be a unique ghost and for it to be quiet.

b. he wants the ghost to be quiet.

Obviously, (15.a) and (15.b) may have a different truth value, that is, Hans may want the ghost to be quiet without wanting the existence of a ghost.

Shoubye is definitely correct in saying that the above attitude ascriptions have different truth conditions. Yet, the question arises whether the presuppositional analysis cannot in fact capture this difference. As a matter of fact, Heim's prominent analysis (1992) cannot distinguish between the meanings of (15.a) and (15.b). ${ }^{7}$ Yet, if we appeal to some other theories of presuppositions which deal with attitude ascriptions, we will be able to show that these sentences are not equivalent, since the presupposition that there exists a ghost-triggered by the embedded clause in (15.b) - will be analyzed as one that escapes the scope of the attitude verb (see Geurts 1998 or Maier 2015 for concrete formal analyses ${ }^{8}$ ). However, if we modify the example a little bit, we will get a sentence that will have a problematic reading according to these theories, despite the fact that the mere presuppositional analysis will be correct. This will show that the problem with the Substitutivity Principle is not related to an inadequate analysis of the presupposition behavior. Consider the following two ascriptions:

(15) Hans believes that there exists a ghost and

c. he wants the ghost to be a quiet ghost.

\footnotetext{
7 I sketch here a computation, using Heim's own notation. In Heim's view, a meaning of sentence $p$ is represented as a (possibly partial) function from contexts (i.e., a set of possible worlds) to contexts, and it is defined only for those contexts where all the worlds satisfy the presuppositions of $p$. For the sake of brevity, I will introduce some abbreviations for all subclauses in (15):

(15-BEL): Hans believes that there to exists a unique ghost,

(15a-WANT): Hans wants [15a-SP] the ghost to be quiet,

(15b-WANT): Hans wants [15b-EX] there to exists a unique ghost and for it to be quiet.

The meanings of (15.a) and (15.b) are defined respectively as (cf. Heim 1992: 197-198):

$(c+15 \mathrm{BEL})+15 \mathrm{a}-\mathrm{WANT}=\left\{w^{*} \in c+15\right.$-BEL: for every $w^{\prime} \in \operatorname{Dox}_{H}\left(w^{*}\right), \operatorname{Sim}_{w}{ }^{\prime}\left(\operatorname{Dox}_{H}\left(w^{*}\right)\right.$ $+15 \mathrm{a}-\mathrm{SP})<_{H, w^{*}} \operatorname{Sim}_{w}\left(\operatorname{Dox}_{H}\left(w^{*}\right)+\right.$ Not:15a-SP $\left.)\right\}$.

$(c+15-\mathrm{BEL})+15 \mathrm{~b}-\mathrm{WANT}=\left\{w^{*} \in c+15\right.$-BEL: for every $w^{\prime} \in \operatorname{Dox}_{H}\left(w^{*}\right), \operatorname{Sim}_{w}{ }^{\prime}\left(\operatorname{Dox}_{H}\left(w^{*}\right)\right.$ $+15 \mathrm{~b}-\mathrm{EX})<_{H, w^{*}} \operatorname{Sim}_{w^{\prime}}\left(\operatorname{Dox}_{H}\left(w^{*}\right)+\right.$ Not:15b-EX) $\}$.

In order to demonstrate that these meanings - taken as context-change potentials - make exactly the same updates, it is enough to show that for every $w^{*} \in c+15$-BEL, $\operatorname{Dox}_{H}\left(w^{*}\right)+15 \mathrm{a}-\mathrm{SP}=\operatorname{Dox}_{H}\left(w^{*}\right)$ $+15 \mathrm{~b}-\mathrm{EX}$ and that the analogical equation holds for the negations, i.e., for every $w^{*} \in c+15$-BEL, $\operatorname{Dox}_{H}\left(w^{*}\right)+$ Not:15a-SP $=\operatorname{Dox}_{H}\left(w^{*}\right)+$ Not:15b-EX. Let $w^{*} \in c+15$-BEL. Given that in every $w^{\prime} \in$ $\operatorname{Dox}_{H}\left(w^{*}\right)$ there exists a single ghost in $w^{\prime}$ (cf. 1992: 189, Definition 18), $\operatorname{Dox}_{H}\left(w^{*}\right)+15$ a-SP is defined and has exactly the same output as $\operatorname{Dox}_{H}\left(w^{*}\right)+15 \mathrm{~b}-\mathrm{EX}$ - it is the subset of $\operatorname{Dox}_{H}\left(w^{*}\right)$ where the unique ghost is quiet. On the other hand, $\operatorname{Dox}_{H}\left(w^{*}\right)+\operatorname{Not}: 15 \mathrm{a}-\mathrm{SP}=\operatorname{Dox}_{H}\left(w^{*}\right) /\left(\operatorname{Dox}_{H}\left(w^{*}\right)+15 \mathrm{a}-\mathrm{SP}\right)$ and $\operatorname{Dox}_{H}\left(w^{*}\right)+$ Not:15b-EX $=\operatorname{Dox}_{H}\left(w^{*}\right) /\left(\operatorname{Dox}_{H}\left(w^{*}\right)+1\right.$ 5b-EX) (cf. 1992: 185, Def. 6); therefore if the first equation holds, so does the second.

${ }^{8}$ I am indebted to an anonymous referee for bringing this fact to my attention.
} 
d. he wants there to be a ghost and for it to be quiet.

The first version (15.c) is reported by native speakers to be "true" in the story about Hans, while the second (15.d) is definitely not. ${ }^{9}$ The problem is that many formal analyses of attitude ascriptions based on possible-worlds semantics seem to predict that (15.c) entails (15.d). Take Maier (2015) for example. In his account-set in the framework of DRT - the mental representations of (15.c), (15.d) would have the following forms ${ }^{10,11}$ :

Given the semantic system presented by Maier (2015, sec. 3.2), the subDRS in the scope of "Att" in DRS-15d (Fig. 1) will capture the mental state of Hans if the corresponding subDRS in DRS-15c (Fig. 2) does so. ${ }^{12}$

The above observation signalizes that prominent theories of presuppositions cannot capture the difference between (15.c) and (15.d) in the sense that the latter is validated by the former within the formal semantic frameworks adopted by those theories. Most importantly, we can see that the problem with the Substitutivity Principle is a phenomenon quite independent from the issue of how presuppositions behave in attitude ascriptions. The problem that (15.c) counter-intuitively validates (15.d) seems to be generated by the fact that in (15.c), the information that there exists a ghost in the state of affairs desired by Hans is smuggled in the modified nominal "a quiet ghost". Hence, although the presupposition of the existence of a

\footnotetext{
9 A short experimental study involving 57 subjects has confirmed this prediction.

${ }^{10}$ I omit here a reconstruction of the whole process of interpretation of these attitude ascriptions (which involves creating some initial DRSes, merging and binding-cf. Maier 2015, sec. 5.2-5.3) and include only these representations which are the outputs of this process; the fact how we come to these interpretations is not relevant for my current purposes.

11 For the sake of simplicity, I represent the modified nominal "quiet ghost" as the conjunction of conditions: Ghost(...), Quiet(...). What is relevant is that the interpretation of the nominal is obviously subsective, namely, it entails that the subject is a ghost. A correct interpretation of "a quiet ghost" seems to be simply intersective, that is, it entails "being a ghost" and "being quiet." (For further discussion on modified nominals see: Heim and Kratzer 1998, sec. 4.3; Morzycki 2013).

12 Here is a rough argument for this. (In the formalization below, I abbreviate the subDRS of DRS-15c which is in the scope of "Att(x)" as " $K c$ " and the corresponding subDRS in DRS-15d as " $K d$ ". Apart from this, I employ Maier's notations and definitions, in particular, I use " $K c_{D E S}$ " to refer to the subDRS of $K c$ which is in the scope of $D E S$ and " $K c_{B E L}$ " to refer to $K c-K c_{\text {DES }}$ etc; let $w$ be any possible world to which we relativize the computation.)
}

\section{Assumption:}

(a) $\operatorname{Dox}\left(\right.$ hans, w) $\subseteq\left[\left[K c_{B E L}\right]\right]$,

(b) for all $c \in \operatorname{Dox}($ hans, $w)$ and $f$ with $f \vDash_{c} K c_{B E L}, B u l^{*}(h a n s, w, c) \subseteq\left[\left[K_{D E S}\right]\right]^{f}$

Claim:

(a*) $\operatorname{Dox}\left(\right.$ hans, w) $\subseteq\left[\left[K d_{B E L}\right]\right]$,

(b*) for all $c \in \operatorname{Dox}\left(\right.$ hans, $w$ ) and $f$ with $f F_{c} K d_{B E L}, B u l^{*}($ hans, $w, c) \subseteq\left[\left[K d_{D E S}\right]\right]^{f}$ (Def. 37, sec. 3.2) Part ( $\mathrm{a}^{*}$ ) of the Claim trivially follows from the part (a) of the Assumption, since the "belief-parts" of the mental states of Hans are exactly the same in both $K c$ and $K d$. Assume $c \in \operatorname{Dox}$ (hans, w) and fix $f$ with $f \vDash_{c} K d_{B E L}$; let $c^{*} \in B u l^{*}(h a n s, w, c)$. To show: $c^{*} \in\left[\left[K d_{D E S}\right]\right]^{f}$. From Assumption (and the fact that $\left.K c_{B E L}=K d_{B E L}\right)$ we can conclude that $c^{*} \in\left[\left[K c_{D E S}\right]\right]^{f}$, which means that there is an embedding function $g \supseteq f$ such that $\operatorname{Dom}(g)=U\left(K c_{D E S}\right)$ and $g \vDash_{c^{*}} K c_{D E S}$ (cf. Defs. 30 and 31). The last condition means that $g(y) \in I_{c^{*}}($ Ghost $)$ and $g(y) \in I_{c^{*}}($ Quiet $)$. We need to consider a function $g * \supseteq g$ such that $\operatorname{Dom}\left(g^{*}\right)=U\left(K d_{D E S}\right)$ and $g *(z)=g(y)$ (technically, we add the pair $(z, g(y))$ to $g$ itself and obtain $\left.g^{*}\right)$. It is enough to realize that $g^{*}$ verifies $K d_{D E S}$ and trivially $g^{*} \supseteq f$, and this implies that $c^{*} \in\left[\left[K d_{D E S}\right]\right]^{f}$ (again, Defs. 30 and 31$)$. 


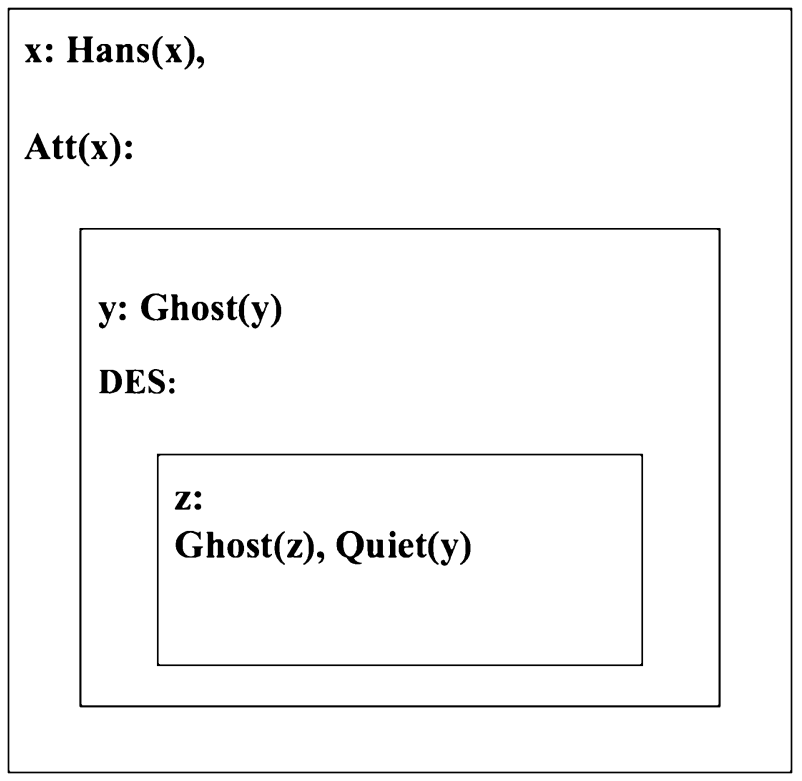

Fig. 1 Discourse representation structure of (15.d) (DRS-15d)

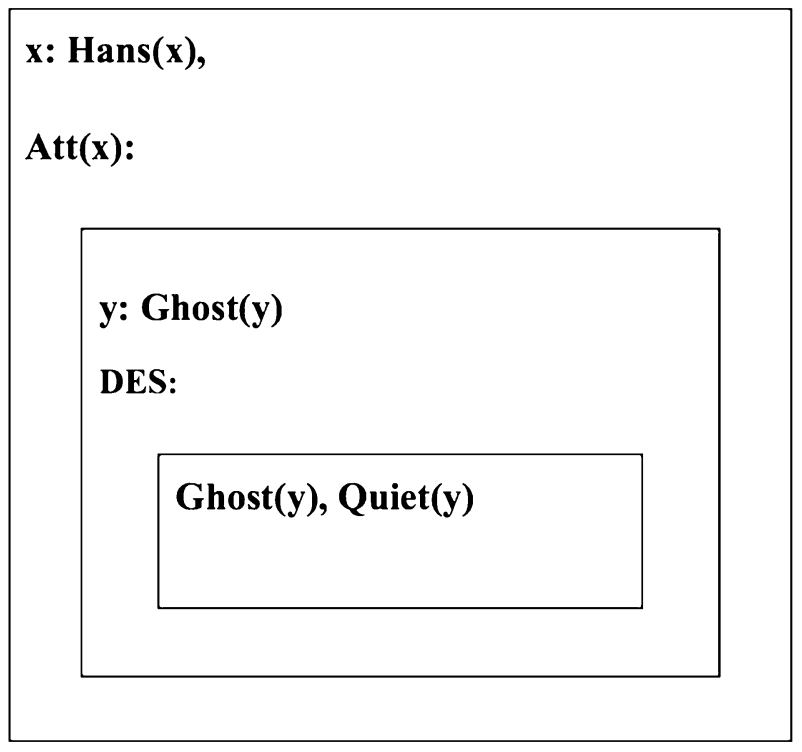

Fig. 2 Discourse representation structure of (15.c) (DRS-15c)

ghost disappears from the scope of desire in (15.c), the asserted content of the embedded clause entails that the individual is a (quiet) ghost, which, in turn, entails that there exists a ghost (and it is quiet). In other words, although we eliminate the 
problematic component entailing the existence of a ghost from the scope of "wants"- thanks to our presuppositional analysis-it "comes back" in the asserted content as a consequence of using an adjective combined with a noun. This shows that no matter how well we treat presuppositions, the problem with the Substitutivity Principle may show its teeth anyway.

Another kind of evidence against the presuppositional explanation of the problem with the Substitutivity Principle is that there are cases where the principle fails but there are no apparent presuppositional differences between the embedded clauses of the ascriptions. The following pairs include typical instances of entailments:

(16) a. Fred lied in court. $F$

b. Fred was in court at least once.

a. The president has been assassinated. $F$

b. The president is dead.

Observe now that these (b)-entailments do not project out of non-monotonic environments, which is good evidence that they are not presuppositions of the (a)sentences. Consider some examples with negations and conditionals:

(18) a. Fred did not lie in court. (He lied in a private conservation and has never been in court.)

b. If Fred has ever lied in court, I do not want to hire him.

(19) a. The president has not been assassinated by the kidnappers. (Luckily, he is still alive.)

b. If the president has been assassinated by the kidnappers, I will be very sad. (I hope that he is still alive.)

As we may observe, neither (18.a) nor (18.b) presupposes that Fred was in court and a similar remark can be made about (19.a), (19.b) - none of these presupposes that the president is dead. Treating these examples as representative, we may conclude that the entailments (16.b), (17.b) do not generally survive embeddings and thus are not presuppositions of (16.a), (17.a). Consequently, the following pairs of sentences which are plainly equivalent do not differ in terms of their presuppositions $^{13}$ :

(20) a. Fred lied in court $\Leftrightarrow$

b. Fred was in court at least once and Fred lied in court.

a. The president has been assassinated $\Leftrightarrow$

b. The president is dead and he has been assassinated.

\footnotetext{
13 The set of presuppositions of " $p$ and $q$ " (in short, $\operatorname{Pres}(p$ and $q)$ ) is defined as the union: $\operatorname{Pres}(p) \cup$ $(\operatorname{Pres}(q) /$ Entailments $(p)$ ), where "Entailments $(p)$ " denotes the set of entailments of $p$ (cf. Karttunen 1974: 179). Consider, for instance, (21). Provided that two sentences "The president has been assassinated" and "The president is dead" have—as the only presupposition—-the claim that there exists a unique president, it is easy to calculate, based on the aforementioned equation, that both sides of (21) presuppose the existence of a unique president and nothing more. A similar argument applies to (20).
} 
Observe now that it is not difficult to come up with examples of non-doxastic attitude ascriptions containing these sentences as the embedded clauses, which have significantly different truth conditions. Consider:

(22) a. Anna regrets that Fred lied in court.

b. Anna regrets that Fred was in court at least once and that Fred lied in court.

a. I wonder whether the president has been assassinated.

b. I wonder whether the president is dead and he has been assassinated.

Ascription (22.a) says that Anna regrets Fred's lying in court and not his being in court, while (22.b) clearly commits Anna to regret the latter. Ascription (23.a) can be true when I know that the president is dead and wonder whether his death was natural or he has been killed; on the other hand, (23.b) plainly assumes that it is a part of my wondering whether the president is dead.

To conclude, we see that the problem with the Principle of Substitutivity is not restricted to the cases with presuppositional differences, and this shows that any explanation of the problem which appeals to the theory of presupposition projection does not get to the heart of the puzzle.

\subsection{Two features of non-doxastic attitudes}

In this subsection, I want to say a few words about why the Principle of Substitutivity fails and in particular, to specify what circumstances actually entail its failure. Before I move on to my explanation, some further clarifications are in order. I do not aim by any means to present in this subsection a full-blown theory of nondoxastic attitude ascriptions, a theory which, among others, is able to fully predict what modifications of the embedded clauses in such ascriptions preserve the truth conditions and what modifications do not. Developing such an account is beyond the scope of this paper. What I only aim to show is that a there is a certain kind of a modification which alternates the truth conditions and that the examples with descriptions (i.e., examples (2) and (3)) actually involve this kind of modification.

In my view, the Principle of Substitutivity fails in the cases where non-doxastic attitude ascriptions exhibits two features (in presenting these features, I use "want" as a paradigmatic example of a non-doxastic attitude verb). The first one has been actually recognized by Kaplan, namely, non-doxastic attitude verbs do not support entailments:

\section{Feature 1}

There are cases in which $S$ wants that $p, p$ entails $q$, but $S$ does not want that $q$.

As we have already seen, there are good examples which illustrate the above claim. The second feature of the non-doxastic attitude verbs is that they usually support at least some kinds of entailments, in particular, the following one:

\section{Feature 2}

If $S$ wants that $p$ and $q$, then $S$ wants $p$ and $S$ wants $q$.

This assumption seems to be very plausible in light of the meaning of "and". When I say that I want $p$ and $q$ to be the case, I intuitively mean that I want both conjuncts to be the case, i.e., I want $p$ and I want $q$. That is, non-doxastic attitude verbs support conjunction elimination. 
Some theorists have suggested that "wants" does not actually support conjunction elimination. Namely, there are cases where someone wants both that $p$ and $q$, but does not want $p$ at the same time. Consider the following statements:

(24) Nicolas wants to fly on the Concorde and pay nothing for the trip,

(25) John wants to swim in the shark-infested waters and survive. ${ }^{14}$

For example, assume that Nicolas does not want to spend all his savings on buying a ticket for a Concorde flight but he would like to fly on the Concorde if someone else paid for his flight. In such a case, (24) is intuitively true, while (26) seems to be false:

(26) Nicolas wants to fly on the Concorde.

A similar story can be made about (25). Nonetheless, I am not entirely convinced that (24) is a real counterexample to Feature 2. The problem is that the intuition saying that (26) is false in the described circumstances is not fully appealing. Observe that falsity of (26) entails that Nicolas does not want to fly on the Concorde, but this claim sounds contradictorily in the context of (27):

(27) \# Nicolas wants to fly on the Concorde and pay nothing for the trip. And he does not want to fly on the Concorde.

It is infelicitous to say that Nicolas does not want to do $p$ right after saying that he wants to do $p$ under such-and-such conditions. However, if both claims are compatible and true, how can we then explain the infelicity? Naturally, it would not be infelicitous to add that Nicolas does not want fly on the Concorde under any condition-but this is not what is claimed here.

Another way to highlight the conflict between the negation of (26) and (24) is to consider a situation of responding "Yes/No" to a straight question whether Nicolas wants to fly on the Concorde. Consider the following dialogue between Mary and Nicolas:

M: Do you want to fly on the Concorde?

N: \# No, I want to fly on the Concorde and not pay for it.

Observe that a denial of the content of the question sounds somewhat infelicitous when the respondent at the same time claims that he wants to fly and not pay for it. Again, this suggests that (26) cannot be false (or its negation cannot be true) when (24) is true. A quite similar doubt can be rephrased with respect to (25).

Altogether, it is questionable whether $(24) /(25)$ is a good counterexample to the claim that non-doxastic attitude support conjunction elimination (Feature 2). The reason why it appears to be so is, in my view, a result of confusing two ways of understanding desire ascriptions. Firstly, the ascription "I want $p$ " may simply express that $p$ is, for some reasons, attractive to me. For example, flying on the Concorde may be attractive because of the feeling of speed. Let me call this kind of

\footnotetext{
14 These counterexamples were brought to my attention by an anonymous referee. The first one comes from Asher (1987: 171) and was adapted here with a slight modification.
} 
attitudes "straight desires". Secondly, by saying "I want $p$ ", I may convey a thought equivalent to "I want $p$ all things considered", "all in all, I want $p$ ". In this case, the ascription should be interpreted as an expression of the subject's willingness to take up a certain activity, which is based on careful considerations including an estimation of all benefits and possibilities of risks of taking up that activity. For example, I may want to work in my own country all things considered, because I have come to the conclusion that it is more important to me to be close to my family than to get a better salary abroad. (Still, working abroad may be attractive to me.) Let me call this second kind of wanting "a rational desire". It is important to emphasize that wanting $p$ all things considered does not entail wanting $p$ no matter what will eventually happen. For example, I may want to fly on the Concorde all things considered, because I have taken into account the fact that plane accidents are extremely rare; however, if I were informed that the plane would be shot down, I would certainly not want to fly on the Concorde in such a case. Wanting $p$ all things considered implies that—so far as I know-obtaining $p$ does not exclude fulfilling my other desires which are more important to me than $p$ itself (like saving my life and etcetera).

The ascriptions of the two indicated kinds of desires are not equivalent in the sense that $S$ may have a straight desire while not having a rational desire of doing $p$. This will be the case when $p$ is attractive to $S$, but she has different desires which stay in conflict with $p$, that is, cannot be jointly fulfilled with $p$, and which are stronger or more important to her; thus, in such a case, $S$ does not have a rational desire of $p$, that is, she does not want $p$ all things considered.

When it comes to examples (24) and (25), I would say that Nicolas does not want to fly on the Concorde all things considered, but he does want to fly in the sense that a ride on the Concorde is attractive to him. Similarly, John does not want to swim with sharks all things considered (because he does not want to die-which is a stronger desire than, e.g., making an impression on his friends). But he may want to swim with sharks in the straight sense, that is, in order to make an impression on his friends. So the intuition that (26) is false is an effect of taking it as an ascription of the rational desire. However, (26) is true when interpreted as an ascription of the straight desire. Altogether, "wants" seems to support conjunction elimination so far as we understand it as a feature of straight desires ascriptions.

Finally, let me observe-quite independently from the above considerationsthat a rejection of Feature 2 would be problematic in itself. In most cases, ordinary speakers of language seem to infer the conclusion that $S$ has attitude $A$ towards $p$ (or towards $q$ ), once they learn that " $S A$ es $p$ and $q$ ". If we reject Feature 2, how are we going to explain that the inferences like the following ones are intuitively valid?

(28) a. Fiona wonders whether to go the cinema and visit Joan beforehand.

b. So Fiona wonders whether to go to the cinema.

(29) a. Johnny wants to have a dog and to go for a walk with it every day.

b. So Johnny wants to have a dog.

It seems that the conclusions (28.b), (29.b) simply follow from the premises (28.a), (29.a) respectively. In passing, let me note that Shoubye (2013, ft. 18) acknowledges 
that it is reasonable to infer the conclusion that Hans wants there to be a unique ghost in his attic from (3) (repeated below)

(3) Hans wants there to be a unique ghost in his attic and for it to be quiet.

What licenses this conclusion is exactly Feature 2.

Once we agree that non-doxastic attitude verbs support conjunction elimination but do not generally support entailments, the Principle of Substitutivity is no longer valid. We can demonstrate it briefly below.

\section{The Argument against Principle of Substitutivity}

For the sake of indirect proof, assume that the Principle of Substitutivity is actually valid. From Feature 1, we know that there is $S, p, q$ such that (i) $S$ wants that $p$, (ii) $p$ entails $q$, (iii) $S$ does not want $q$. Fix such $S, p$, $q$. Consider the statement " $q$ and $p$ ". Observe that since $p$ entails $q$, the statement " $q$ and $p$ " is equivalent to $p$. From the Principle and (i), we derive " $S$ wants that $q$ and $p$ ". From Feature 2, we can conclude then that $S$ wants that $q$; contradiction with (iii).

The argument shows that the Principle of Substitutivity fails in light of the fact that non-doxastic attitudes have Features 1 and 2. More importantly, it shows how a counterexample to the Principle can be made. Take such $p$ and $q$ that exemplify Feature 1; observe that the conjunction " $q$ and $p$ " is actually equivalent to $p$; assuming Feature 2, you already have got a counterexample to the Principle of Substitutivity: $p$, " $q$ and $p$ ".

In my view, the example involving definite descriptions actually belongs to the indicated class of counterexamples to the Principle of Substitutivity (assuming perhaps slight adjustments). Firstly, let us observe that the following entailment holds:

(30) a. The ghost in the attic is quiet. $F$

b. There is a unique ghost in the attic.

This seems to be correct, though the way how we exactly characterize this relation depends on the treatment of definite descriptions. On the quantificational account, (30.b) is a logical consequence of (30.a); on the presuppositional account, in turn, it is claimed that a felicitous utterance of the first one presupposes the second one. However, it is important to observe that even on this account, we may say that the truth of (30.a) "guarantees" the truth of (30.b) in the sense that a felicitous utterance of the former-the one which expresses the truth or falsehood-requires the latter to be satisfied (in other words, provided that (30.a) expresses the truth in a context, it suffices to conclude that (30.b) must also be true). Secondly, we assume that in the context of the story about the ghost, Hans wants (30.a) but not (30.b) to be the case (Feature 1). Thirdly, we observe that (30.a) is equivalent to a sentence being a conjunction of it and (30.b) (written below as (31)): ${ }^{15}$

\footnotetext{
15 I am not saying that (30.a) and (31) have the same meaning. On the presuppositional account, (30.a) triggers a presupposition which (31) does not have. But even on such an account, we must agree that the truth of the former guarantees the truth of the latter and vice versa.
} 
(31) There is a unique ghost in the attic and the ghost in the attic is quiet.

However, Hans does not want (31) to be the case. It is because this ascription implies - in line with Feature 2-that Hans wants there to be a unique ghost. Altogether, the example with definite descriptions is constructed in such a way that it falls into exactly this class of counterexamples to the Principle of Substitutivity, which is indicated in the above argument. (Let me note here that even if one insists that not all non-doxastic attitude ascriptions support conjunction elimination, the example with the ghost does not seem to be the case where this principle actually fails.)

Altogether, the consideration of this section delivers the conclusion that the failure of the Principle of Substitutivity is a result of the fact that non-doxastic attitude ascriptions support only some kinds of entailments, particularly, conjunction elimination. As I emphasized at the beginning, by saying that this principle fails, I do not mean that every substitution of the embedded clause in a non-doxastic attitude ascription with an equivalent clause must produce a difference in the truth conditions. Obviously, there can be modifications of the embedded clause which preserve the truth conditions. For example, consider the following pair:

a. I want Sarah to be exactly 5 min late.

b. I want Sarah to be late and her delay to be exactly $5 \mathrm{~min}$.

It is hard to imagine a situation in which (32.a) would have a different truth-value than (32.b). One may wonder what I can say about these cases. As I have said, I have not promised a full account of non-doxastic attitude ascription. Nonetheless, I believe that a certain explanation can be offered, based on what was said above.

What I have established is that when $S A$ es that $p, p$ entails $q$, and $S$ does not $A$ that $q$, then we have a counterexample to the Principle of Substitutivity ( $p, " q$ and $p$ "). Certainly, it would not be a counterexample if $S$ Aes that $p$ and Aes that $q$, contrary to the earlier assumption. However, observe that this situation actually obtains in the above case (32). Namely, if I want Sarah to be exactly $5 \mathrm{~min}$ late, then I want her to be late (at least, such a general desire can be ascribed to me). Hence, no confusion arises if someone says that I want both, i.e., I want Sarah to be late and her delay to be precisely 5 min-which is exactly what (32.b) says. In general, my hypothesis is that a modification of the embedded clause alternates the truth conditions of an ascription if and only if-roughly speaking-it "splits" the clause into separate "pieces" (which are entailed by the clause and which, taken together, entail the clause itself) and the subject does not hold the attitude in question towards some of these "pieces". In the above case, we do not encounter such a phenomenon.

Finally, I want to indicate a certain corollary of the above analysis of nondoxastic attitude ascriptions. As it is usually assumed, attitude ascriptions are generally statements of relations between the subjects and "propositional contents". That is to say, " $A$ " used in " $S A$ es that $p$ " expresses a relation between $S$ and the propositional content of $p$. However, in light of the above observations, our choice of an account of propositional contents is somehow limited. Namely, we cannot adopt any account which implies that analytically equivalent sentences actually express the same proposition. Provided that such sentences express the same 
propositions, a hopeless puzzle arises of how it is possible that they yield different truth conditions while being embedded under propositional operators. To sum up, an important upshot of my analysis of non-doxastic attitude ascriptions is that, given the propositional-accounts, only the fine-grained conceptions of propositions are correct (e.g., Larson and Ludlow 1993; King 2013).

Another corollary of my analysis is that the semantics of attitude ascriptions must be more complicated than one expects as they do not allow for even such "innocent" substitutions as the ones illustrated by examples (22.a, b), (23.a, b). We need a characterization which will block the inferences from (a)-sentences to (b)sentences in these pairs of ascriptions - one which is surely more sophisticated than Hintikka's or even Stalnaker's semantic frameworks. It is worth saying at this point that many philosophers or linguists have recently signalized various problems concerning some specific features of attitude ascriptions and proposed elaborated semantical analyses which focus on addressing these particular problems, and they step away from the standard accounts (e.g., see Anand and Hacquard 2013 on epistemic modals embedded in attitude ascriptions, or Ninan 2012 on de re uses of the ascriptions of counterfactual attitudes).

\section{Conditionals and concluding remarks}

Throughout this paper, I have argued that the objection involving non-doxastic attitude ascriptions does succeed in showing that the quantificational theory of descriptions is wrong. Firstly, I have observed that a proponent of that theory is committed to the view that subject-predicate sentences are "only" analytically equivalent to the corresponding existential sentences. In light of this observation, the objection requires the Principle of Substitutivity. Secondly, I have argued that this principle faces many counterexamples and its limitation cannot be explained away by a presuppositional analysis. Thirdly, I have suggested that the failure of the principle is a result of two features of non-doxastic attitude ascriptions, i.e., the fact that they support conjunction elimination and do not support all kinds of entailments at the same time.

Finally, I want to briefly address the issue of conditionals which, according to some theorists, raise the same problem for the quantificational theory as attitude ascriptions. Elbourne and Schoubye claim that this theory assigns incorrect truth conditions to conditional statements such as (33):

(33) If the ghost in the attic is quiet tonight, Hans might finish his thesis.

On the quantificational analysis, the antecedent of (33) should be represented as "[The $x$ : Ghost $(x)]($ Quiet $(x)) " 16$ and thus the whole sentence seems to be equivalent to:

16 Provided that we assign a narrow-scope to the definite description. Elbourne and Schoubye observe that the problem discussed here does not arise when we ascribe the wide-scope reading to "the ghost" in (33); nevertheless, a defense of the quantificational account based on the claim that in a sentence of this 
(34) If there is a unique ghost in the attic and it is quiet tonight, Hans might finish his thesis.

However, (34) is non-equivalent to (33) as the former has a clear implication that there exists a ghost in the attic, while the latter does not.

Some people have expressed doubts whether my defense of the quantificational theory is on the right track since it says nothing about conditionals which seemingly pose a similar problem for this theory. However, I think that the examples with attitude ascriptions and conditionals (such as (2) and (33)) actually illustrate two different problems for that theory. The first problem is quite general and concerns the attitude ascriptions and conditionals as well. The problem is that sentences such as (2) and (33) intuitively have such implications which the quantification account cannot explain. Apparently, (2) implies (35) below and (33) implies (36) below:

(35) Hans believes that there is a ghost in the attic.

(36) There is a ghost in the attic.

The quantificational theory as it stands cannot justify these implications (call it "Problem 1"). This is not a problem I have addressed in this paper but will say a few words about it below. The second problem is that the quantificational account seemingly assigns some unwanted implications to (2), that is, the implication that Hans wants the existence of a ghost. However, observe that no similar difficulty arises for conditionals: (34) does not have any extra implication with respect to (33). To summarize - the quantificational theory faces two problems: attitude ascriptions and conditionals do not have implications they ought to have (Problem 1); attitude ascriptions-and this exclusively concerns this kind of sentences-have implications which they should not have (Problem 2).

As one may realize, Problem 2 is actually the one I have addressed in my paper and tried to show that it rests on a mistaken assumption concerning the substitutivity. So the particular problem I have targeted is strictly related to attitude ascriptions, and the reservations that I have not analyzed conditionals are inappropriate here. As far as Problem 1 is concerned, I think that a solution has been actually suggested by Schoubye. He observes that once we combine the quantificational with the presuppositional analysis, we are ready to explain where the implications of (2) and (33) (i.e., (35) and (36) respectively) come from. ${ }^{17}$ As Schoubye puts it, "this would not really be a Russellian view, but it might be close enough." Subsequently, the author complains that this solution is insufficient, because even if we add the presuppositional requirement, the quantificational theory still continues to predict incorrect truth conditions of (2) (cf. example (15.a,b)). However, he overlooks the fact (not surprisingly as he does not distinguish Problem 1 and Problem 2) that the combined account is not problematic in the case of

Footnote 16 continued

form, the description in the subject position takes obligatorily a wide scope is unpromising for several reasons (see: Schoubye 2013: 500).

17 This explanation appeals to presupposition projection (see Sect. 2.1). 
conditionals. In order to realize this, let us apply Schoubye's reasoning about attitude ascriptions to conditionals. Suppose that the presupposition of (33) is satisfied, i.e., there is a unique ghost in Hans's attic. It is hard to imagine that, under this assumption, (33) could have a different truth value than (34). Philosophers disagree on what an adequate semantic analysis of conditionals is, but most of them accept "Ramsey Test" in one or the other form. Generally speaking, this test provides the following procedure of evaluating "If $p$, then $q$ ": add $p$ hypothetically to your stock of beliefs (adjust this stock in a minimal way, if necessary) and on the basis of this, evaluate $q$; your verdict about $q$ is the verdict about the conditional itself. Observe now that when we add to our stock of beliefs-which already contains a belief that there is a unique ghost in the attic-either "The ghost in the attic is quiet" or "There is a unique ghost in the attic and it is quiet", the outputted stocks of beliefs are basically the same. Hence, the consequent is evaluated in the same way in each case, and as a result conditionals (33) and (34) get the same verdicts. The fact that the application of Ramsey Test to (33) and (34) delivers the same results under the condition that the presupposition of (33) is satisfied indicates that these sentences may have the same asserted content, despite the presuppositional difference. If that is correct, the presuppositional strategy solves Problem 1.

Altogether, the case of conditionals and non-doxastic attitude ascriptions illustrates two different problems and the aim of this paper was to target only one of them-the puzzle about the attitude ascriptions. Hopefully, I have been successful in demonstrating that this problem rests on a mistaken assumption concerning the nature of non-doxastic attitude ascriptions.

Acknowledgements This article is a part of the research supported by a grant of National Science Center in Poland (Decision No. UMO-2013/09/N/HS1/02024). I wish to thank Cezary Cieśliński and Justyna Grudzińska for their comments and suggestions which were very helpful in preparing a revised version of my manuscript.

Open Access This article is distributed under the terms of the Creative Commons Attribution 4.0 International License (http://creativecommons.org/licenses/by/4.0/), which permits unrestricted use, distribution, and reproduction in any medium, provided you give appropriate credit to the original author(s) and the source, provide a link to the Creative Commons license, and indicate if changes were made.

\section{References}

Abbott, B. (2000). Presuppositions as nonassertions. Journal of Pragmatics, 32(10), 1419-1437.

Anand, P., \& Hacquard, V. (2013). Epistemics and attitudes. Semantics and Pragmatics. doi:10.3765/sp. 6.8 .

Asher, N. (1987). A typology for attitude verbs and their anaphoric properties. Linguistics and Philosophy, 10, 125-198.

Elbourne, P. (2005). Situations and individuals. Cambridge, MA: MIT Press.

Elbourne, P. (2010). The existence entailments of definite descriptions. Linguistics and Philosophy, 33(1), $1-10$.

Elbourne, P. (2013). Definite descriptions, series: Oxford studies in semantics and pragmatics. Oxford: OUP. 
Geurts, B. (1998). Presuppositions and anaphors in attitude contexts. Linguistics and Philosophy, 21(6), 545-601.

Heim, I. (1992). Presupposition projection and the semantics of attitude verbs. Journal of Semantics, 9(3), $183-221$.

Heim, I., \& Kratzer, A. (1998). Semantics in generative grammar, series: Blackwell textbooks in linguistics. Oxford: Blackwell Publishers Ltd.

Kaplan, D. (2005). Reading 'On denoting' on its centenary. Mind, 114, 933-1003.

Karttunen, L. (1974). Presuppositions and linguistic context. Theoretical Linguistics, 1, 181-194.

King, J. (2013). On fineness of grain. Philosophical Studies, 163(3), 763-781.

Larson, R. K., \& Ludlow, P. (1993). Interpreted logical forms. Synthese, 95(3), 305-355.

Maier, E. (2015). Parasitic attitudes. Linguistics and Philosophy, 38(3), 205-236.

Morzycki, M. (2013). The lexical semantics of adjectives: More than just scales. In M. Morzycki (Ed.), Modification, series: Key topics in semantics and pragmatics. Cambridge: Cambridge University Press.

Neale, S. (1990). Descriptions. Cambridge, MA: MIT Press Books.

Neale, S. (2005). A century later. Mind, 114, 809-871.

Ninan, D. (2012). Counterfactual attitudes and multi-centered worlds. Semantics and Pragmatics. doi:10. 3765/sp.5.5.

Pupa, F. (2013). Embedded definite descriptions: A novel solution to the familiar problem. Pacific Philosophical Quarterly, 94(3), 290-314.

Ramachandran, M. (2009). Descriptions with an attitude problem. Philosophical Quarterly, 59(237), $721-723$.

Russell, B. (1905). On denoting. Mind, 14, 479-493.

Schoubye, A. (2013). Ghosts, murderers, and the semantics of descriptions. Nous, 47(3), 496-533.

Stalnaker, R. (1984). Inquiry. Cambridge, MA: MIT Press. 